\title{
Waterfalls as sources of small charged aerosol particles
}

\author{
L. Laakso ${ }^{1}$, A. Hirsikko ${ }^{1}$, T. Grönholm ${ }^{1}$, M. Kulmala ${ }^{1}$, A. Luts ${ }^{2}$, and T.-E. Parts ${ }^{2}$ \\ ${ }^{1}$ Department of Physical Sciences, P.O. Box 64, 00014 University of Helsinki, Finland \\ ${ }^{2}$ Institute of Environmental Physics, University of Tartu, Ülikooli 18, 50090 Tartu, Estonia
}

Received: 22 June 2006 - Published in Atmos. Chem. Phys. Discuss.: 26 September 2006

Revised: 28 February 2007 - Accepted: 23 April 2007 - Published: 4 May 2007

\begin{abstract}
In this study, we measured the mobility distributions of cluster and intermediate ions with an ion spectrometer near a waterfall. We observed that the concentration of negative $1.5-10 \mathrm{~nm}$ ions was one-hundred fold higher than a reference point $100 \mathrm{~m}$ away from the waterfall. Also, the concentration of positive intermediate ions was found to be higher than that at the reference point by a factor of ten. This difference was observed only at the smallest sizes; above $10 \mathrm{~nm}$ the difference was insignificant.
\end{abstract}

\section{Introduction}

Aerosol particle formation in the atmosphere is a significant factor affecting both climate and the ecosystem. In addition to large-scale particle formation (Kulmala et al., 2004), new particles are also observed to form on a limited spatial scale. One special case of nucleation mode particle appearance is the breakup of small water droplets (Hõrrak et al., 2005, 2006). These observations show the formation of new, especially negatively-charged intermediate ions related to rain. Recent model calculations suggest that intermediate air ion formation may also take place near waterfalls (Luts et al., 2004).

The effect of waterfalls on the electrical status of the adjacent environment has been known for more than a century. As early as as the 1890 s, Lenard (1892) showed that air becomes negatively charged near waterfalls. He also demonstrated that the effect only arises when moving liquid is sprayed at an obstacle. A simple water jet, for example, was found to generate no such effect. Different water-related electrical measurements (e.g. Wilson cloud chamber) were the frequent target of studies in the late 19th century. Flagan

Correspondence to: L. Laakso

(lauri.laakso@iki.fi)
(1998) and the references therein provide a thorough review of these early measurements.

Many have studied the formation of charged droplets, especially in the context of sea spray. Blanchard $(1958,1966)$ studied charged droplets released from bursting bubbles. In his studies, he found that: 1) drops smaller than four $\mu \mathrm{m}$ are always positively charged, and 2) the larger drops can be either positive or negative depending on the history of the bubble Blanchard (1958). Later on, Gathman and Trent (1968) and Klusek et al. (2004) also studied charges related to bubbles and sea spray.

In 1994, Reiter measured, in addition to sea spray, ions produced by waterfalls. He found that particles from sea spray smaller than $200 \mathrm{~nm}$ carried a net positive charge whereas similar particles from waterfalls were negatively charged. He attributes the difference in polarity to the different chemical compositions of river and sea water. Reiter also performed some tests with water containing different chemical impurities, and found that the polarity indeed depended on the suspended material: added sodium chloride produced positive particles whereas pure water and Mediterranean sea water produced negative ions.

Recently, several authors have discussed charge formation (e.g., ion evaporation, the Coulomb explosion, charge residue) in liquid droplets (Iribarne and Thomson, 1976; Znamenskiy et al., 2003, 2006; Vostrikov et al., 2006). Their experiments showed that in some cases small ions can separate from evaporating charged droplets.

Despite prior knowledge, however, previous studies focus on large particle sizes, and there are no number size distribution measurements of cluster and intermediate ions have been carried out in the vicinity of a waterfall. The case of waterfalls differs from, for example, rain, since bulk water is originally electrically neutral whereas rain droplets may be originally charged due to their formation in the clouds. 


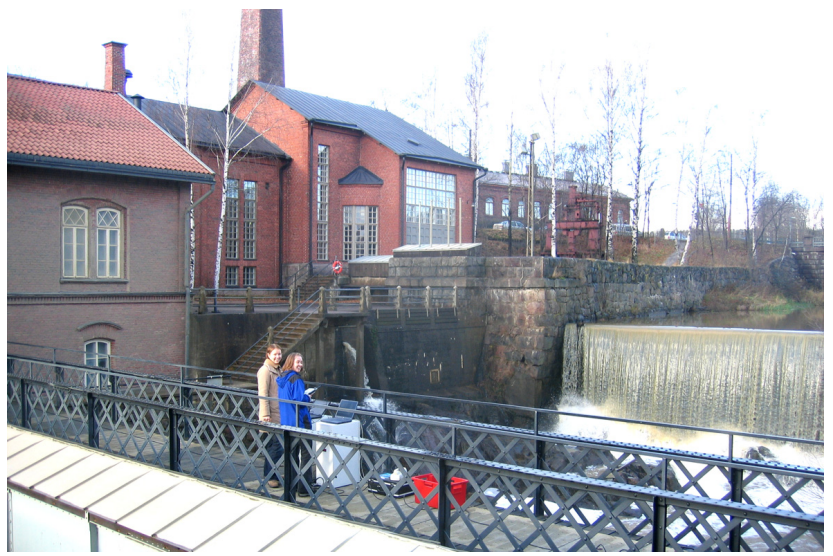

Fig. 1. The Vanhankaupunginlahti barrage with two happy measurers. The AIS took measurements from the bridge. The reference measurement point was about $100 \mathrm{~m}$ to the right (East) of the bridge. The closest road is located behind the building in the middle of the picture.

\section{Instruments}

We measured waterfall-produced ions with two Air Ion Spectrometers (AIS) (Laakso et al., 2004; Airel Ltd.). AISs measure the mobility distributions of air ions: naturally-charged clusters and aerosol particles. The spectrometer consists of two identical cylindrical aspiration-type differential mobility analysers: one for measuring positive ions and the other, for negative ions. Each mobility analyser has 21 collector electrodes provided with individual electrometrical amplifiers for measuring the electrical current carried by ions of different mobilities. The air sample containing ions is sucked into the mobility analyser through the electronically-controlled electrostatic filter (switched on/off). The filter removes (switched on) the ions from the sample when the offset levels of the measuring electronics are measured for data quality monitoring purposes. Otherwise, the filter is switched off. The time resolution of the AIS is typically five minutes, the time used in our experiments. During that time sample and offset level, mobility distributions are measured in turn.

Estimations of diffusion broadening and losses of ions and data inversion are based on a theoretical treatment by Airel Ltd (Fuchs, 1964; Tammet, 1970). Recently, the AISs and their inversion procedure have been calibrated in the laboratory down to $2 \mathrm{~nm}$ and less by comparing the devices to the other type of ion spectrometer, Balanced Scanning Mobility Analyzer (BSMA, Airel Ltd), which is considered an etalon device (Tammet, 2004, 2006).

In our experiments, the mobility range of AISs was $0.00133-3.16 \mathrm{~cm}^{2} \mathrm{~V}^{-1} \mathrm{~s}^{-1}$. The mobility distributions of ions are presented by 28 logarithmically uniformly distributed fractions. According to Tammet's algorithm (1995), the diameter range is 0.34 to $40 \mathrm{~nm}$ at normal temperature and pressure $(273 \mathrm{~K}$ and $1 \mathrm{~atm})$, which are assumed here when converting the mobilities to diameters. We must note that conversion from mobility to diameter assumes only one charge per cluster/particle. In the atmosphere, this assumption is sufficient for small particles due to their low charging probability (e.g. Fuchs, 1964). However, in the case of waterfalls, artefacts of size can arise if droplets are multiple charged, depending on their formation processes.

In addition to air ion spectrometers, we used a Delta OHM DO 9847 logger with Pt100 and Mk-33 sensors to measure temperature, relative humidity and pressure. The total aerosol particle number concentration was measured with two TSI Model 3007 condensation particle counters with a cut-off size of $10 \mathrm{~nm}$. The two CPCs were compared side by side with ambient particle concentrations of 2000 to $40000 \mathrm{~cm}^{-3}$ and the results were corrected by the offset factor (equal to 0.9) obtained from the comparison, with the lower concentration as a reference.

\section{Measurements}

The measurements were carried out at Vantaanputous (Fig. 1), a waterfall ca five kilometre northeast of downtown Helsinki, Finland. The waterfall is located near a road located around $100 \mathrm{~m}$ from the measurement point. The River Vantaa is a typical river of Southern Finland with a relatively high clay content. On 15 November 2005, the total suspended mass (measured with $0.4 \mu \mathrm{m} \mathrm{mem-}$ brane filters $1.4 \mathrm{~km}$ upriver from our measurement point) was $100 \mathrm{mg} /$ litre (personal communication with K. Lahti and Vahtera et al., 2005). The height of the fall is approximately $10 \mathrm{~m}$ which produces a maximum velocity of $14 \mathrm{~ms}^{-1}$ assuming free gravitational fall.

We carried out our measurements on two days: 11 and 18 November 2005. Both days were relatively cold with high humidity (Table 1). On 11 November we measured for $1.5 \mathrm{~h}$ and on 18 November for over $4 \mathrm{~h}$.

We used two air ion spectrometers: one on the bridge approximately $20 \mathrm{~m}$ from the edge of the waterfall and a reference measurement $100 \mathrm{~m}$ from the waterfall to the side of the mean wind. Wind direction was measured with the humid finger method, and these empirical data, together with visual estimation of the traffic density on different roads to choose the reference point. Due to technical problems (a locked gateway) during the second measurement day, the AIS on the bridge was located on the eastern end of the bridge.

Before starting the measurements, we compared the two AISs by running them side-by-side for an hour to detect any possible offset between the devices. When interpreting the charged particle concentrations and size distributions, the AIS data at the waterfall was multiplied by the sizedependent coefficients obtained from comparison measurements. The average correction factor for positive ions was 1.02 and for negative ions, 1.23 . We assumed that differences between the AISs were the same during the experiments. 
Table 1. Basic characteristics of the two observation days.

\begin{tabular}{|c|c|c|}
\hline & 11 November 2005 & 18 November 2005 \\
\hline Median $\mathrm{T}\left[{ }^{\circ} \mathrm{C}\right]$ & 9.8 & 0.8 \\
\hline Median RH [\%] & 76.5 & 71.0 \\
\hline Water flow $\mathrm{m}^{3} \mathrm{~s}^{-1}$ & 10.9 & 22.8 \\
\hline $\mathrm{N}_{\text {tot }}(\mathrm{ref})\left[\mathrm{cm}^{-3}\right]$ & 19978 & 24649 \\
\hline $\mathrm{N}_{\text {tot }}$ (water fall) $\left[\mathrm{cm}^{-3}\right]$ & 14909 & 27412 \\
\hline \multicolumn{3}{|l|}{ Difference (waterfall - reference) } \\
\hline Negative ions $1.5-10 \mathrm{~nm}\left[\mathrm{~cm}^{-3}\right]$ & 5410 & 1565 \\
\hline Positive ions $1.5-10 \mathrm{~nm}\left[\mathrm{~cm}^{-3}\right]$ & 562 & 220 \\
\hline
\end{tabular}
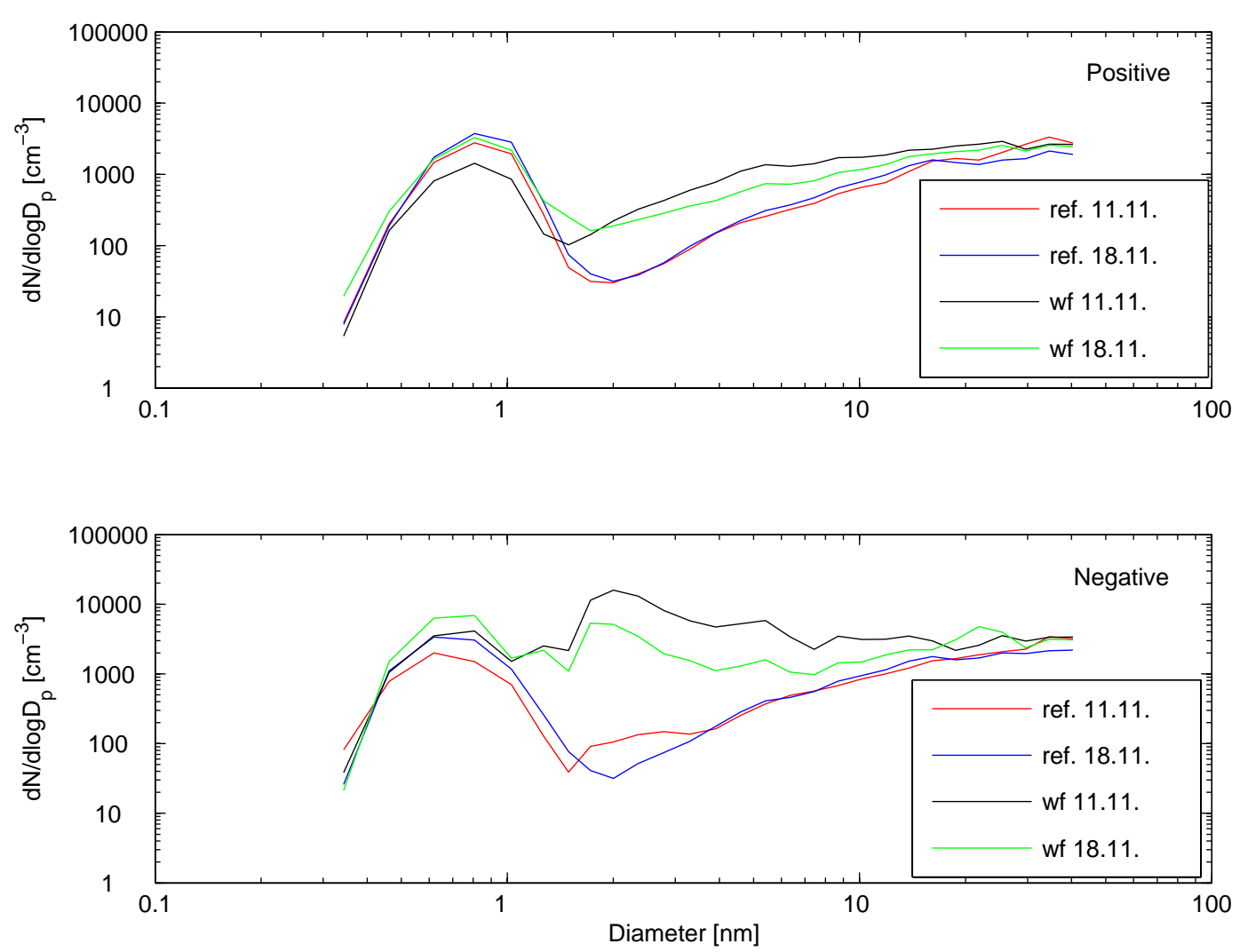

Fig. 2. The median size distributions of positive and negative ions at the waterfall (wf) and at the reference point (ref) (11 and 18 November 2005).

\section{Results and discussions}

Figure 2 shows the size distributions of negative and positive ions. During both days, there was a clear difference between the waterfall and the reference in the concentration of 1.5-10 nm ions. This difference was more pronounced for negative ions, but the concentration of positive ions was also enhanced. When we compared concentrations of negative and positive ions at the reference point from both days, we noticed that the concentrations were relatively equal, as they should be without sign-dependent intermediate ions sources nearby.

Figure 3 presents the ratios of ion concentrations at the waterfall to those at the reference point. The concentration of negative ions in the size range of 1.5 to $10 \mathrm{~nm}$ was up to 120 -fold at the waterfall. The concentration of positive ions also increased approximately ten-fold. The effect of waterfall was visible only in ions smaller than approximately $30 \mathrm{~nm}$. 


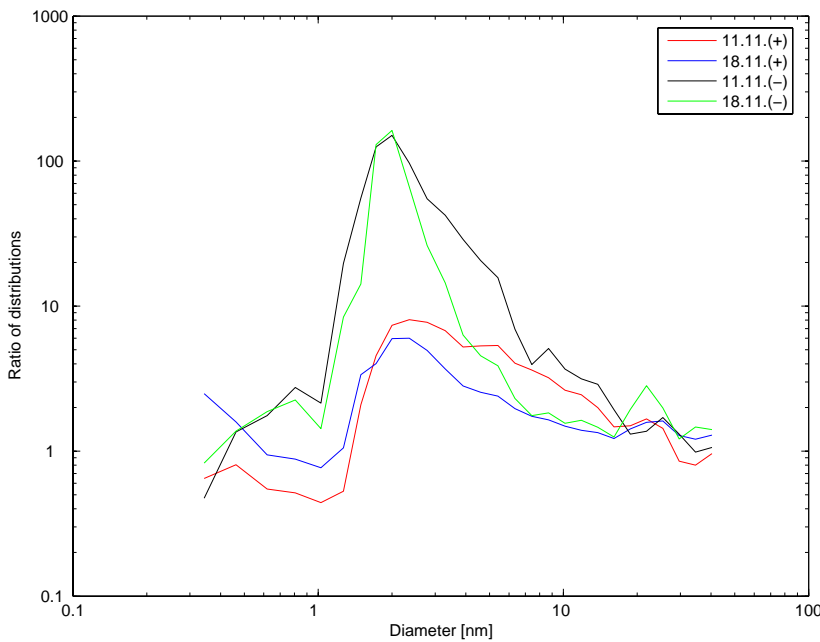

Fig. 3. The ratios of positive and negative ion concentrations at the waterfall to the concentrations at the reference point.

Another interesting feature is the difference in the widths of the distributions between the two days, which may be due to the differences in the autoionisation rates at different temperatures. However, with only two days of data, the reasons for this difference remain speculative. The size of the maximum concentration also differed. The maximum of negative ions is made of up of slightly smaller sizes ( $2 \mathrm{~nm}$ versus $2.5 \mathrm{~nm}$ for positive).

Table 1 summarises the median characteristics of our measurements. The upper size limit for the cluster ions is approximately $1.5 \mathrm{~nm}$. We used that value as a lower limit when calculating differences in the intermediate ion concentrations between the waterfall and the reference point. The table shows a clear difference between the two days on which we performed measurements: on the first observation day, the difference is several times higher than on the second day. This contrasts with the water flow rates in the river Vantaa. We attributed this difference mainly to the differences in wind directions, since measurements of a single point (line) source such as a waterfall are sensitive to even small changes in wind directions. However, the general conclusions for both days are qualitatively similar.

As explained in Sect. 2, we aimed to avoid experimental errors by comparing the devices side-by-side and calibrating them carefully in the laboratory. However, natural sources of errors can also arise which can lead to misinterpretation of the results. One of our main concerns was the possible background contamination of the nearby road. We studied this effect with two portable CPCs and found that the concentrations and their time behaviour were relatively equal at both the waterfall and the reference point (Table 1). However, concentrations at the bridge were slightly higher, probably due to larger $(>10 \mathrm{~nm})$ ions produced by the waterfall.

\section{Conclusions}

In this study, we present the ion size distribution observations in the vicinity of a waterfall. We found that waterfalls produce intermediate-sized, mainly negative ions. The concentration of the negative ions between 1.5 and $10 \mathrm{~nm}$ at the waterfall was more than 100 times higher than at the reference point. Moreover, the concentration of positive ions increased ten-fold. The maximum concentration of waterfall-produced negative ions was at $2 \mathrm{~nm}$, whereas the maximum of positive ions was at $2.5 \mathrm{~nm}$. Our results are in qualitative agreement with those of a previous study by Reiter (1994), assuming that the negative charge of particles smaller than $200 \mathrm{~nm}$ in his study was caused mainly by ions between 1 and $20 \mathrm{~nm}$. The formation of nucleation mode-sized particles from the waterfall is a significant local source of atmospheric condensation nuclei, and may thus affect the atmospheric chemistry. If the nucleation mode particles can grow to larger sizes (around $50-100 \mathrm{~nm}$ ), they may also affect cloud or fog formation or both in the vicinity of a waterfall.

Acknowledgements. The authors wish to thank the following people for their help: J. Ylönen from the Finnish Museum of Technology for his help, and especially for providing us with electricity; M. Huttunen of the Finnish Environment Institute and K. Lahti of the Vantaa River and Helsinki Region water protection society for data related to the river Vantaa; and M. Dal Maso and M. Vana for their help with transportation. A. Hienola is acknowledged for test-reading the manuscript. In addition, the Estonian Science Foundation (grants no. 6223 and 5387) and the Maj and Tor Nessling Foundation (grant no. 123) are acknowledged for their funding of this study.

Edited by: W. Conant

\section{References}

Airel Ltd, E.: http://www.airel.ee, 2007.

Blanchard, D.: Electrically charged drops from bubbles in sea water and their meteorological significance, J. Meteorol., 15, pp. 383395, 1958.

Blanchard, D.: Positive Space Charge from the Sea, J. Atmos. Sci., 23, 507-515, 1966.

Flagan, R.: History of Electrical Aerosol Measurements, Aerosol Sci. Technol., 28, 301-380, 1998.

Fuchs, N. A.: The mechanics of Aerosol, Pergamon, New York, 1964.

Gathman, S. and Trent, E.-M.: Space charge over the open ocean, J. Atmos. Sci., 25, 1075-1079, 1968.

Hõrrak, U., Tammet, H., Aalto, P., Vana, M., Hirsikko, A., Laakso, L., and Kulmala, M.: Formation of charged nanometer aerosol particles associated with rainfall, in: Proceedings of Europian Aerosol Conference 2005, Ghent, Belgium, edited by: Maenhaut, W., p. 606, 2005.

Hõrrak, U., Tammet, H., Aalto, P., Vana, M., Hirsikko, A., Laakso, L., and Kulmala, M.: Formation of charged nanometer aerosol particles associeted with rainfall: atmospheric measurements and 
lab experiments, in: Proceedings of BACCI, NECC and FCoE activities 2005, edited by: Kulmala, M., Lindroth, A., and Ruuskanen, T., vol. 81B of Report Series in Aerosol Science, pp. $180-185,2006$.

Iribarne, J. and Thomson, B.: On the evaporation of small ions from charged droplets, J. Chem. Phys., 64, 2287-2294, 1976.

Klusek, Z., Wisznievski, A., and Jakacki, J: Relatioships between atmospheric positive electric charge densities and gas bubble concentrations in the Baltic Sea, Oceanologia, 46, 459-476, 2004.

Kulmala, M., Vehkamäki, H., Petäjä, T., Dal Maso, M., Lauri, A., Kerminen, V.-M., Birmili, W., and McMurry, P.: Formation and growth rates of ultrafine atmospheric particles: a review of observations, J. Aerosol Sci., 35, 143-176, 2004.

Laakso, L., Anttila, T., Lehtinen, K., Aalto, P., Kulmala, M., Hõrrak, U., Paatero, J., Hanke, M., and Arnold, F.: Kinetic nucleation and ions in boreal particle formation events, Atmos. Chem. Phys., 4, 2353-2366, 2004, http://www.atmos-chem-phys.net/4/2353/2004/.

Lenard, P.: Ub̈er die Elektrizität der Wasserfälle, Ann. Phys., 46, 584-636, 1892.

Luts, A., Noppel, M., and Vehkamäki, H.: Effect of sulfuric acid on the composition of negative small air ions: a numerical simulation, in: J. Aerosol Sci., EAC 2004 abstract book, 2004.

Reiter, R.: Charges on particles of different size from bubbles of Mediterrian Sea surf and from waterfalls, J. Geophys. Res., 99(D5), 10 807-10 812, 1994.
Tammet, H.: The aspiration method for the determination of atmospheric ion-spectra, IPST for NSF, p. 208, 1970.

Tammet, H.: Size and mobility of nanometer particles, clusters and ions, J. Aerosol Sci., 26, 459-475, 1995.

Tammet, H.: Balanced Scanning Mobility Analyser, BSMA, in: Nucleation and Atmospheric Aerosols 2004: 16th International Conference, edited by: Kasahara, M. and Kulmala, M., pp. 294297, 2004.

Tammet, H.: Continuous scanning of the mobility and size distribution of charged clusters and nanometer particles in atmospheric air and the Balanced Scanning Mobility Analyzer BSMA, Atmos. Res., 82(3-4), 523-535, doi:10.1016/j.atmosres.2006.02.009, 2006.

Vahtera, H., Muukkonen, P., Männynsalo, J., and Lahti, K.: Vantaanjoen yhteistarkkailu: Vedenlaatu vuosina 2000-2004, 56, Vantaanjoen ja Helsingin seudun vesiensuojeluyhdistys ry, 2005.

Vostrikov, A. A., Drozdov, S. V., Rudnev, V. S., and Kurkina, L. I.: Molecular dynamics study of neutral and charged water clusters, Computational Materials Science, 35(3), 254-260, doi:10.1016/j.commatsci.2004.12.073, 2006.

Znamenskiy, V., Marginean, I., and Vertes, A.: Solvated ion evaporation from charged water nanodroplets, J. Phys. Chem., 107, 7406-7412, 2003.

Znamenskiy, V., Marginean, I., and Vertes, A.: Molecular dynamics study of neutral and charged water clusters, Computational Materials Science, 35, 254-260, 2006. 